\title{
The Impact of Wave Blocking from Ship Hulls on the Stability of Tg. Piai Coastline
}

\author{
Jacob Hjelmager Jensen, Juan C Savioli, and Khairunnisa Saaban
}

\begin{abstract}
Tg. Piai, located on the southern tip of west Malaysia in Johor, is subject to critical coastal erosion on the east side of the headland, and, as a consequence, severe loss of protected mangrove coastline has been observed over the past 20 years. Various triggers for this erosion have been proposed, all being linked to the extensive developments of the region, and the increase in marine activities in the waters of Singapore Strait. In this study, impacts on the regional (ambient) wave field, by the presence of ships in the Strait of Singapore, are investigated. Waves are partially reflected off the hulls of the ships, and the extensive presence of ships in the Strait of Singapore thus manifests itself as a blocking of the ambient wave field, resulting in a wave climate near Tg. Piai that depend on the congestion of ships. The integrated effect of the ship hull-induced wave reflections on the ambient wave field is evaluated by using the numerical modelling tool MIKE 21. Information on the number, the positions and the sizes of the ships are determined from satellite images. It is found that the impacts of ship hull-induced wave reflections on the near shore wave field at $\mathrm{Tg}$. Piai are significant, and, in particular, that the impacts on near shore wave periods are pronounced. The MIKE 21 model predicts significant reductions in the wave periods at $\mathrm{Tg}$. Piai when including the ships. These changes in the wave periods can explain the changes to the coastal morphology observed at $\mathrm{Tg}$. Piai, including the coastal erosion, from the notion that the longer waves in the wave spectrum tend to push sediment in the coastal profile onshore, whereas the shorter waves moves sediment seaward.
\end{abstract}

Index Terms - Coastal stability, environmental impact, Johor, wave reflection.

\section{INTRODUCTION}

The sizes and numbers of ships (moving as well as being anchored) have increased dramatically in the Straits of Singapore. This is documented in [1] providing detailed statistics on tanker and vessel arrivals to the ports in Singapore. The congestion of ships can be appreciated when flying into Singapore or as an observer facing the sea at the tip of Tg. Piai. In the latter case, the projection of hundreds of ships on the horizon makes up a continuous line. A snapshot from 2012 showing the typical denseness of ships in the northern part of these waters is given in Fig. 1.

Due to the extensive presence of ships, the propagation of (regional) waves, through these waters onto the coastline of

Manuscript received July 10, 2015; revised September 15, 2015.

Jacob Hjelmager Jensen was with Technical University of Denmark. He is now the Technical Director is with DHI Water and Environment (M) Sdn Bhd, Kuala Lumpur, Malaysia (e-mail: jhj@dhigroup.com).

Juan C. Savioli and Khairunnisa Saaban are with Coastal and Marine Department, DHI Water and Environment (M) Sdn Bhd, Kuala Lumpur, Malaysia (e-mail: jcs@dhigroup.com, kns@dhigroup.com).
Tg. Piai, is being disturbed. The impacts of ships on the ambient wave field include the reflection of waves off the hulls of the ships. When waves encounter a vessel, part of the wave energy will be transmitted beneath the ship hull, and part of the wave energy will be reflected off the hull. The degree of reflection depends on the wave (its period, direction and height) to the draft and width of the vessel. In waters with many ships, the reflection/transmission of wave energy leads to a complex sea state, depending not only on the size and the number of ships, but also by their distribution and orientation. To the authors' knowledge, such impacts on waves have never been considered as part of assessing coastal impacts.

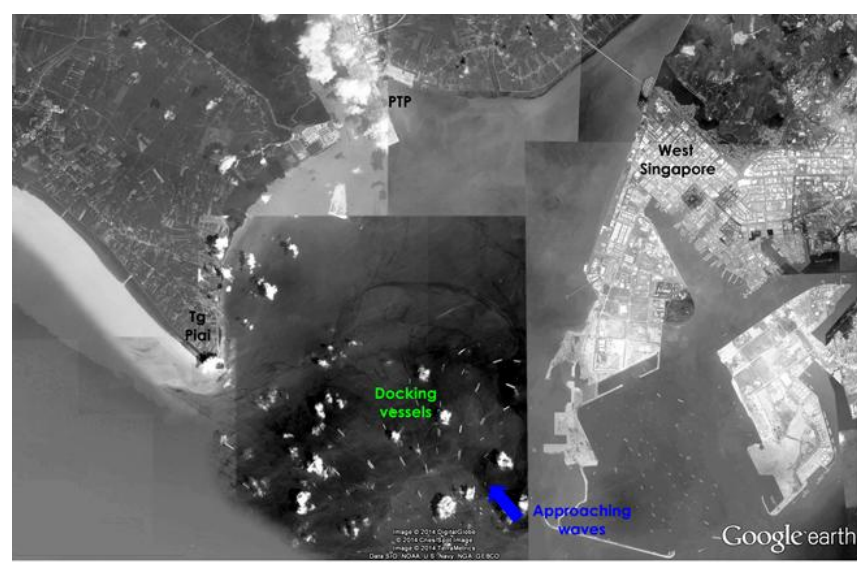

Fig. 1. Tg. Piai and snapshot of ships in parts of the Singapore strait waters

\section{Coastal Settings}

Morphological conditions in the bay located between Singapore and $\mathrm{Tg}$. Piai are characterized by tidal flats, shallow waters and fringing mangrove forests. The morphology is a result of a relatively benign wave and current climate in the bay, and the excess amount of fine sediments present in the Malacca Strait and other regional waters can deposit here. The shallow bay morphology is scoured in the western side of the bay by the Sg. Pulai river flow and ebb/flood tidal flows. These natural channels have in recent time been artificially straightened, deepened and merged into one main channel which accommodates navigation mainly up to the Port of Tanjung Pelepas (PTP). An eastern channel located closer to the Singapore waters connects the Straits of Johor to the outer areas in the Straits of Singapore.

While the westerly side of Tg. Piai shows an accreting coastline with a stable mangrove forest fringe as illustrated in Photo 1 , the easterly side shows an eroding coastline. Here the coastline and mangrove forest is retreating and signs of severe coastal erosion can be observed as shown in Photo 2. Erosion is particularly pronounced immediately north of the National Park monument area. 


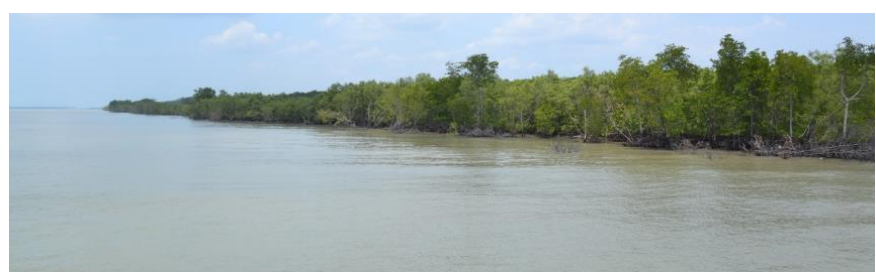

Photo 1. Stable mangrove coastline along the westerly coast of Tg. Piai National Park.

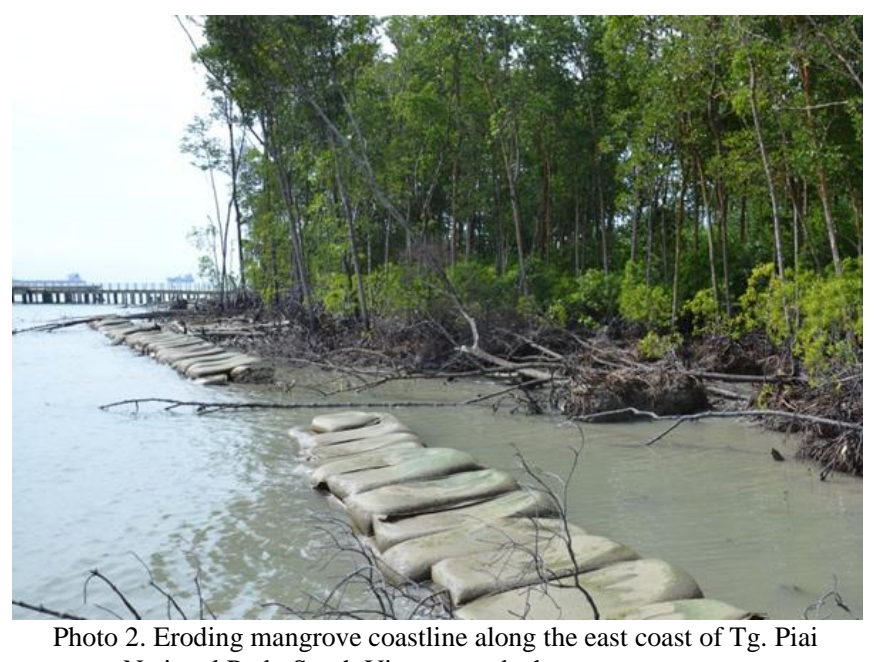

National Park. South View towards the monument area.

The wave climate on the easterly side of Tg. Piai is fundamentally different from that on the north-westerly side. While waves on the north-westerly side are longer, the waves on the easterly side are characterized as short-crested. This difference in wave conditions can be attributed to the orientation of the coastline and the associated wave fetches. During the NE monsoon season the fetch on the east coast is bounded by the proximity of Singapore and therefore short.

The westerly side of Tg. Piai is sheltered from NE monsoon wind waves, and the wave periods at this location were observed to be relatively long. During high tide, it was observed that waves penetrate through the mangrove fringe, and gently dissipate across the muddy bed and around the root stilts. The dissipation of waves occurred mainly by the friction imposed by the roots and mud bed, with little (or no) contribution from wave breaking. The structure of the mangrove root stilts, together with the strength of the natural mud bed, formed a sufficiently strong structure to resist re-suspension and erosion.

Although waves were shorter and smaller in height on the east side of Tg. Piai, as compared to the waves observed on the north-westerly side, the effect of wave breaking on the re-suspension of mud was observed to be more pronounced, which was emphasized by the occasional plunging waves. The wave breaking, associated with a more concentrated decay of wave energy, was seen to induce strong localized erosion of the mud bed inside the mangrove forest. The forces associated with the breaking during high tide were able to slowly damage the mangrove mud bed. The period of rough NE monsoon wave conditions - see also Photo 3 - defines, in combination with high tide events, the most severe condition for coastal stability. Exposing the mangrove fringe to the aggressive combination of short-crested waves and high tide will certainly entail erosion due to offshore-directed transport. The environment and the rough impacts of waves on the mangrove forest seabed on this side of Tg. Piai agree well with the observed erosion of the mangrove forest shoreline.

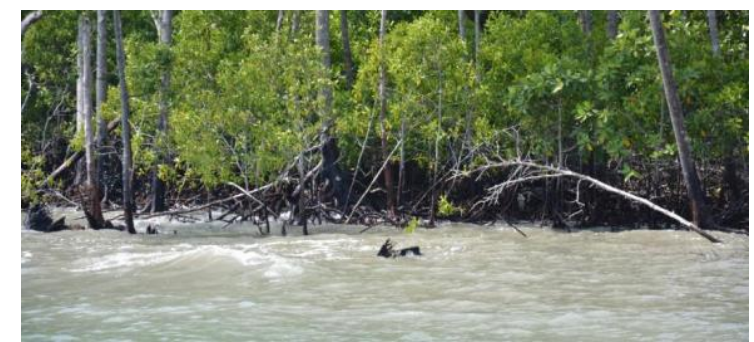

Photo 3. Short-crested waves breaking in front of the mangrove forest line during high water levels.

\section{WAVE MODELLING}

The regional wave field and the potential impacts on the waves and thus the coastline stability at $\mathrm{Tg}$. Piai from ship hull-induced wave reflections are investigated. To determine the wave conditions in the study area it is necessary to compute the wave climate at the site. The wave field is determined by employing the numerical wave modelling system MIKE 21 Spectral Wave (SW) to transform the wave conditions from offshore area into the site. The same model has been used to assess the generation of waves by local wind effects. MIKE $21 \mathrm{SW}$ is a fully spectral model that simulates the growth, decay and propagation of wind-generated waves and swell in offshore and coastal areas. The model includes the following physical phenomena:

- Wave growth by wind action

- Refraction and shoaling due to the seabed variations

- Dissipation due to wave breaking

- Dissipation due to bottom friction

- Dissipation due to white-capping

- Non-linear wave-wave interaction

- Effect of time-varying water depth

- Wave transmission

The modelling tool is also described thoroughly in [2].

Impacts are evaluated by considering the situation with and without the presence of ships in the waters of Singapore Strait. The size, number and distributions of ships in the Strait of Singapore are obtained by digitizing the ships, i.e., extracting front and rear-end coordinates of all ships visible on satellite images (see e.g. the image in Fig. 1). This information is given as input to the MIKE 21 wave model (MIKE $21 \mathrm{SW}$ ) along with a transmission coefficient for each ship. The wave transmission coefficient, Kt, expressing the amount of wave energy transmitted beneath the ship hull, (see, e.g., [3]), is estimated from the experimental work described in [4], and by using linear wave theory (see, e.g. [3]). In [4] the transmission coefficient is given as function of draft and width of floating breakwaters. It is noted, that only the alterations to the ambient wave field from the ship hull-induced wave reflection/transmission are modelled, i.e., wave diffraction around ships, generation of ship wakes from moving vessels etc. are neglected.

\section{RESULTS AND IMPACTS ON WAVES}

Snapshots of the undisturbed wave field, and wave fields 
obtained by using partial (obtained from [4]) and full reflection of the waves off the ship hulls are shown in Fig. 2.

Fig. 2 shows that partial blocking of the wave energy induced by ship hulls have significant impacts on the wave field in the Strait of Johor, and that the wave heights in the nearshore waters east of Tg. Piai are reduced (i.e., compared to the situation with no ships). The changes in wave conditions west of the headland are, however, moderate. Changes in wave conditions on the east side are pronounced, particularly during monsoon seasons, where the resulting wave field displays smaller wave periods and wave heights.

In Fig. 3 and Fig. 4 wave roses for the wave heights and wave periods over a year is presented. The wave roses display how the annual wave height/wave period and wave direction are distributed in time at a particular location. In this case, wave roses are extracted at the locations on the east and west side as well as at the tip of Tg. Piai. Wave roses for the undisturbed $(K t=1)$, and for the cases of partial $(0<K t<1)$ and full reflections $(K t=0)$ are included. Statistics for both the significant wave height (Fig. 3) and the peak wave periods (Fig. 4) are provided. The wave statistics for the partial wave reflection is obtained by using an average transmission coefficient of $K t=0.5$ (corresponding to a mean value of the ships and their estimated draft).

Fig. 3 and Fig. 4 reveal that both the significant wave heights and, in particular, the peak wave periods are reduced due to the blocking of the waves. The pronounced changes to the wave period are due to the filtering of the longer waves in the wave spectrum, which typically approaches from the south Shorter waves are being re-generated over the short fetch from the dedicated anchoring and navigation zones to the coastline of Tg. Piai. The ship-induced filtering of waves is also seen to cause a notable shift in the dominant wave direction in the nearshore waters at Tg. Piai. The ship-induced filtering of waves, taking place in the Strait of Singapore, is seen to generate nearshore waves that a more oblique to the coastline east of Tg. Piai.

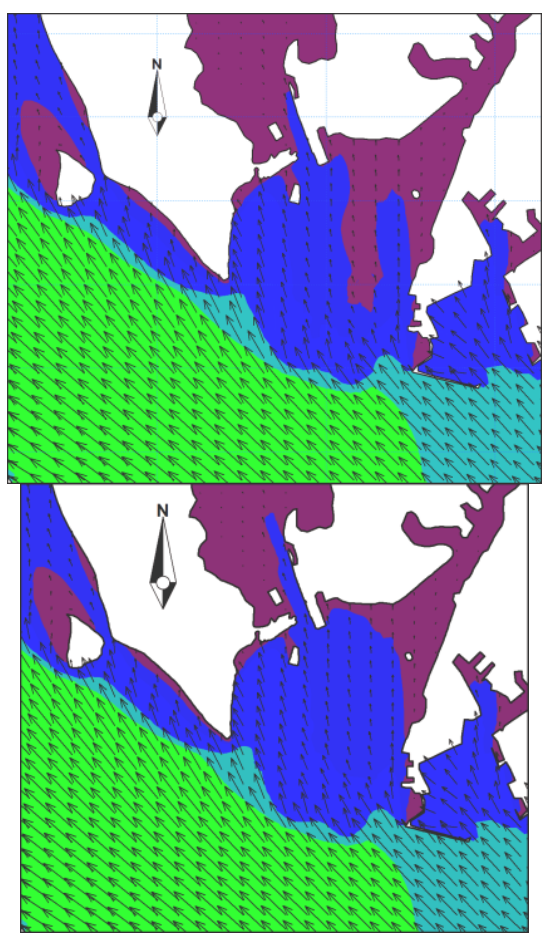

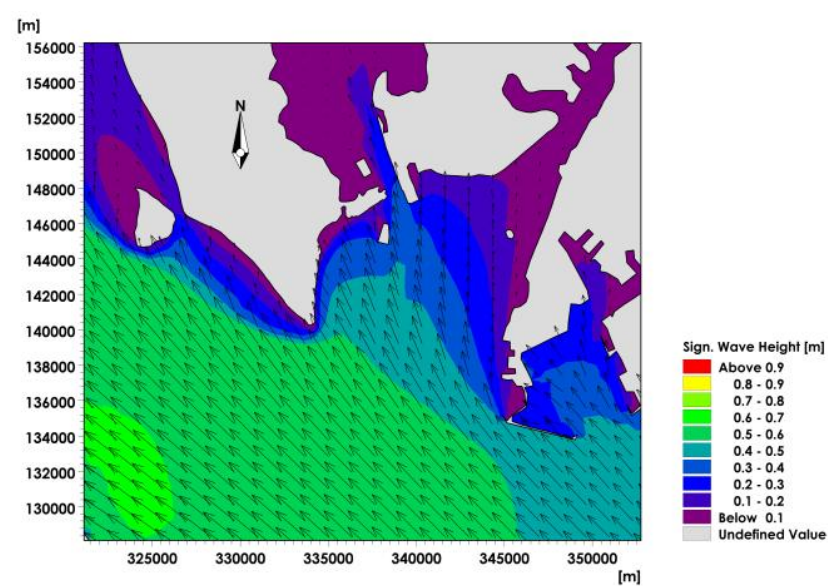

Fig. 2. Predicted wave field with full reflection (top left), partial reflection (top right) and no reflection of waves from vessels (bottom).

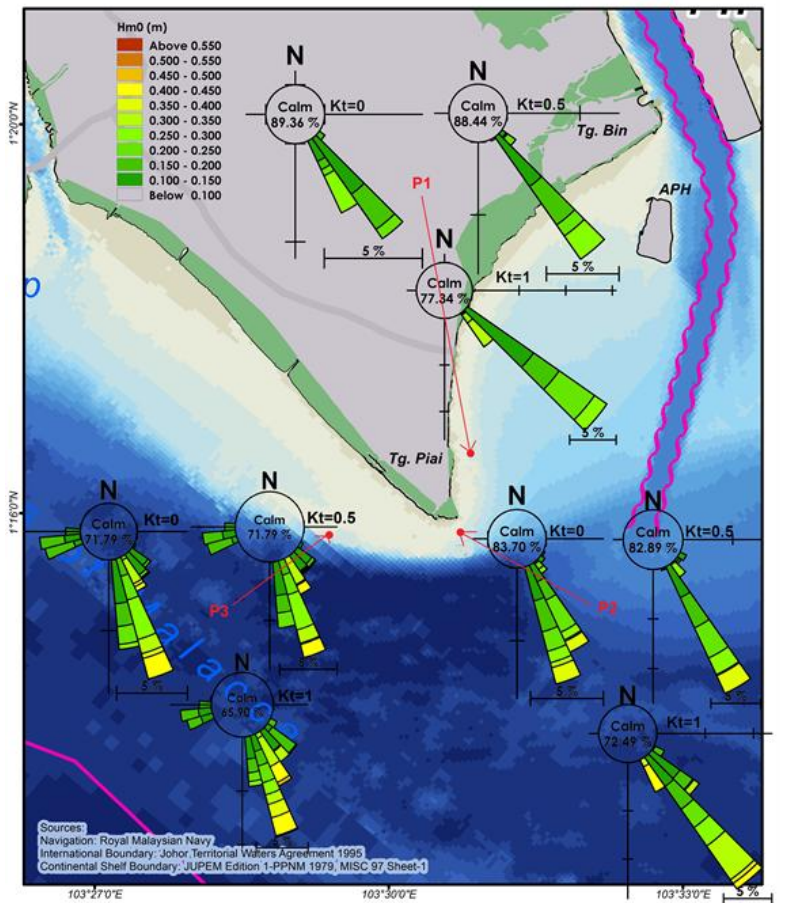

Fig. 3. Wave heights at three locations (east, west and tip of Tg. Piai) for three (3) transmission coefficients.

\section{Potential Impacts on the Mangrove CoAstlines}

The shape of the coastal (cross-shore) profile is known to be sensitive to changes in the wave period, and a change in the wave period will shift the equilibrium of the cross-shore profile. Especially mangrove coastlines, which are characterised by a flat and shallow foreshore, are sensitive to changes in the wave periods. The sensitivity of the cross-shore profile to changes in the wave period is well described in, e.g., [5] and [6]. In [5], the longer waves, in a given wave spectrum, is shown to be responsible for transporting sediment onshore, and these waves thus supply the coast with sediment. The offshore transport, however, is normally induced by the shorter waves in the spectrum. A requirement for a coastline to be stable is that the onshore transport balances or exceeds the offshore transport.

It has been shown above, that the wave periods have decreased significantly in the nearshore waters east of Tg. Piai due to the relatively high congestion of ships in the Strait of Singapore. The reduction in the wave periods will cause a 
reduction in the mechanism that pushes sediment onshore. The shorter waves, however, remain in the wave spectrum, implying that the mechanism for offshore transport is unaltered. In other words, the coastline east of $\mathrm{Tg}$. Piai is exposed to a wave climate that potentially can cause a net loss of material leading to a negative deficit in the sediment budget for the coastal profile. A budget deficit materializes in coastal erosion.

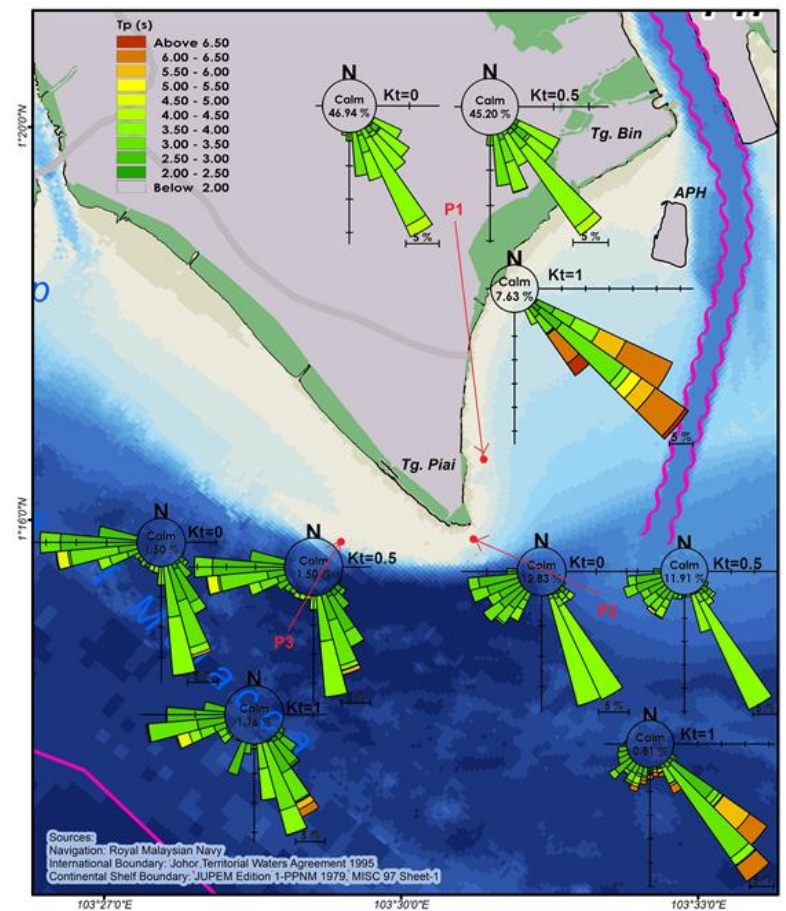

Fig. 4. Wave periods at three locations (east, west and tip of Tg. Piai) for three (3) transmission coefficients.

\section{CONCLUSION}

Over the last decades, marine traffic has boomed in the Strait of Singapore. Detailed numerical modelling of the wave field and the impacts of ship hull-induced wave reflections have revealed that the observed congestion of ships, have changed the wave climate, as compared to the situation with no ships. The observed changes in wave climate along adjacent coastlines are associated with impacts on the coastal morphology. The change in wave climate include a reduction in wave periods, and it is found that this reduction, in particular, is a likely contributing factor to the erosion, and the erosion patterns, observed along the coastline east of $\mathrm{Tg}$. Piai. Interestingly, the mangrove coastline on the west side of the headland is accreting, which can be attributed to the lesser impact from the ships/development on waves here.

\section{REFERENCES}

[1] Singapore Port Information by the Hydrographic Department of Maritime and Port Authority of Singapore, 2013.

[2] DHI, "MIKE 21 spectral wave module. Scientific documentation," DHI Water \& Environment, 2013.

[3] C. C. Mei, "The applied dynamics of ocean surface waves," World Scientific, Advanced Series on Ocean Engineering, vol. 1, 1989.

[4] E. Koutandos, E. Prinos, and X. Gironella, "X. Floating breakwaters under regular and irregular wave forcing: Reflection and transmission characteristics," Journal of Hydraulic Research, vol. 43, no. 2, 2005.

[5] J. C. Winterwerp, P. L. A. Erftemeijer, N. Suryadiputra, P. Eijk, and L. Zhang, "Defining eco-morphodynamic requirements for rehabilitating eroding mangrove-mud coasts," Wetlands, Springer, 2013.

[6] K. Mangor, "Shoreline management guideline," DHI Water \& Environment, 2004.

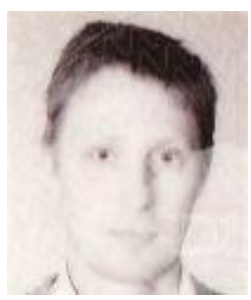

Jacob Hjelmager Jensen was born in Denmark. He obtained his educational degree from the Technical University of Denmark in M. Sc., civil engineering, 1995 and Ph.D., in CFD and sediment transport modelling, 1998.

He has more than 15 years of international experience within coastal and marine engineering consultancy and is an expert in the areas of coastal and marine hydraulics, coastal morphology and sedimentation problems. He is now currently the technical director of DHI Water \& Environment (Malaysia) following a position as an associate professor with the Technical University of Denmark. Previous articles published can be found on Google scholar. 